\title{
Robotic TAMIS for local excision of ultra-distal neoplasia
}

\author{
R. L. Shuck ${ }^{1}$ - S. W. Larach ${ }^{1}$. S. Atallah ${ }^{1}$
}

Received: 17 March 2019 / Accepted: 26 March 2019 / Published online: 15 April 2019

(c) Springer Nature Switzerland AG 2019

Precision has always been a cornerstone of robotic surgery, with the idea being that if dissection is more exact, the improvement in operative quality will translate into superior clinical outcomes. The advantage of precision-based local excision of rectal neoplasia has been proven [1]; whether performed by transanal minimally invasive surgery (TAMIS) [2] or by transanal endoscopic microsurgery (TEM) [3] the outcome remains the same [4].

Introduced in 2011, robotic TAMIS was proposed as a technique which could be applied toward local excision of rectal neoplasia, and preliminary data confirm feasibility and acceptable outcomes [5, 6]. Such a natural orifice approach, utilizing robotics, likely represents a key target application for next-generation computer-enhanced surgical systems [7, 8].

In this video forum, the da Vinci Xi surgical system (Intuitive Surgical, Sunnyvale, CA, USA) in conjunction with TAMIS access is used as a platform to excise a rectal neoplasm which encroaches on the anterior anal verge. The technical challenges posed by ultra-distal access and exposure, as well as the general principles of TAMIS-based robotic local excision, are detailed.

\section{Compliance with ethical standards}

Conflict of interest Dr. S. Atallah reports consultancy (such as consulting fees and honoraria) from Medtronic Inc., Applied Medical, ConMed Inc, and Medrobotics. Dr. S. Larach holds stock options with Applied Medical Inc. R. Shuck has no disclosures to report.

Ethical approval This research was performed in accordance with the ethical standards of the institutional and/or national research committee

Electronic supplementary material The online version of this article (https://doi.org/10.1007/s10151-019-01975-2) contains supplementary material, which is available to authorized users.

S. Atallah

atallah@post.harvard.edu

1 HCA North Florida Division, Winter Park, FL, USA and with the 1964 Declaration of Helsinki and its later amendments or comparable ethical standards.

Informed consent Informed consent was obtained in accordance with the standards set forth by hospital regulations.

\section{References}

1. Moore JS, Cataldo PA, Osler T, Hyman NH (2008) Transanal endoscopic microsurgery is more effective than traditional transanal excision for resection of rectal masses. Dis Colon Rectum 51(7):1026-1030

2. Lee L, Burke JP, deBeche-Adams T, Nassif G, Martin-Perez B, Monson JRT, Albert MR, Atallah SB (2018) Transanal minimally invasive surgery for local excision of benign and malignant rectal neoplasia: outcomes from 200 consecutive cases with midterm follow up. Ann Surg 267(5):910-916

3. Winde G, Nottberg H, Keller R, Schmid KW, Bünte H (1996) Surgical cure for early rectal carcinomas (T1). Transanal endoscopic microsurgery vs. anterior resection. Dis Colon Rectum 39(9):969-976

4. Lee L, Edwards K, Hunter IA, Hartley JE, Atallah SB, Albert MR, Hill J, Monson JR (2017) Quality of local excision for rectal neoplasms using transanal endoscopic microsurgery versus transanal minimally invasive surgery: a multi-institutional matched analysis. Dis Colon Rectum 60(9):928-935

5. Lee SG, Russ AJ, Casillas MA Jr (2018) Laparoscopic transanal minimally invasive surgery (L-TAMIS) versus robotic TAMIS (R-TAMIS): short-term outcomes and costs of a comparative study. Surg Endosc. https://doi.org/10.1007/s00464-018-6502-8 (Epub ahead of print)

6. Tomassi MJ, Taller J, Yuhan R, Ruan JH, Klaristenfeld DD (2019) Robotic transanal minimally invasive surgery for the excision of rectal neoplasia: clinical experience with 58 consecutive patients. Dis Colon Rectum 62(3):279-285

7. Marks J, Ng S, Mak T (2017) Robotic transanal surgery (RTAS) with utilization of a next-generation single-port system: a cadaveric feasibility study. Tech Coloproctol 21(7):541-545

8. Warren CD, Hamilton AER, Stevenson ARL (2018) Robotic transanal minimally invasive surgery (TAMIS) for local excision of rectal lesions with the da Vinci Xi (dVXi): technical considerations and video vignette.Tech Coloproctol 22(7):529-533. https:// doi.org/10.1007/s10151-018-1816-z (Epub 2018 Jul 10)

Publisher's Note Springer Nature remains neutral with regard to jurisdictional claims in published maps and institutional affiliations. 